permanência no meio de enraizamento e a época do ano não influênciaram na taxa de sobrevivência das mudas, variando entre 92,19 e $100 \%$. As paradas de crescimento das mudas micropropagadas, mantidas em casa de vegetaçāo, devem ser causadas por dormência, pois após um período de $1440 \mathrm{~h}$, sob temperatura de $2 \mathrm{a} 4^{\circ} \mathrm{C}$, as plantas recuperaram o crescimento.

TÍTULO: Ultraestrutura de Aulacoseira granulata (Ehr.) Sim. e A. ambigua (Grun.) SIM. (Bacillariophyta).

AUTOR: Rosemeri Segecin Moro

DATA: 20 de dezembro de 1991

NÍVEL: Mestrado

LOCAL: Universidade Federal do Paraná

BANCA EXAMINADORA: Ita Moema Valente Moreira - UFPR (orientador)

Denise de Campos Bicudo - IBSP

Thelma Alvin Veiga Ludwig - UFPR

RESUMO: Realizou-se um estudo comparativo morfológico entre as células vegatativas de cinco táxons pertencentes ao grupo Aulacoseira (=Melosira) granulata: A. granulata (Ehr.) Sim. var. granulata, A. granulata (Ehr.) Sim. var. angustisima (O. Muller) Sim., A. granulata (Ehr.) Sim. var. australiensis (Grun.) Moro. A. ambigua (Grun.) Sim. var. ambigua e A. ambigua (Grun.) Sim. var. ambigua f. spiralis (Skuja) Ludwig, amostradas em 24 meses na Represa Alagados, Ponta Grossa (Pr). Efetuou-se uma revisão da terminologia empregada para a descriçāo do grupo visando a sua uniformizaçāo em língua portuguesa. As análises foram realizadas sob microscopia fotônica e eletrônica de varredura para todos os cinco táxons, e microscopia eletrônica de transmissāo para $A$. granulata var. australiensis em particularr. Este trabalho pretende ser uma contribuiçāo ao conhecimento das espécies e, em especial, à classificaçāo de $A$. granulata var. australiensis e A. ambigua var. ambigua $\mathrm{f}$. spiralis, que tiveram novas combinaçōes nomeclaturais propostas recentemente e sāo analisadas pela primeira vez sob microscopia eletrônica de varredura.

\title{
Universidade Federal de Pernambuco - UFPE
}

TÍTULO: Composição e biomassa do fitoplâncton na Baía de Guajará (Brasil).

AUTOR: Rosildo Santos Paivà

DATA: Fevereiro de 1991

LOCAL: Universidade Federal de Pernambuco

NÍVEL: Mestrado

BANCA EXAMINADORA: Enide Eskinasi Leça UFPE (orientadora)

Geraldo Mariz, - UFPE

Maryse N. Paranaguá, - UFPE

RESUMO: A composição, biomassa e comportamento do fitoplâncton da Baía do Guajará (Pará-Brasil), foram estudados através de amostras coletadas a cada dois meses, entre 
·dezembro/1989 e outubro/1990. As análises basearam-se em amostras de plancton obtidas horizontalmente na superfície com auxílio de uma rede com malhas de $65, \mu \mathrm{m}$ de abertura. No estudo quantitativo do fitoplâncton determinou-se a densidade (células/litro) e concentração de clorofila "a" $\left(\mathrm{mg} / \mathrm{m}^{3}\right)$. Salinidade da água, temperatura, transparência e $\mathrm{pH}$ foram mensurados, para comparaçāo. $\mathrm{O}$ fitoplâncton foi composto por 116 taxa específicos e infraespecíficos: 1 . Cyanophyceae, 45 Chlorophyceae e 70 Bacillariophyceae. Mais significativos foram: Polymyxus coronalis (indicador de águas salobras amazônicas)e Actinoptychus trilingulatus (primeiro registro para o Brasil). Quantitativamente o fitoplâncton variou de 790.000 cél/lit. a 4.790 .000 cél/lit, sendo mais abundantes os fitoflagelados, seguidos pelas distomaceas, cianofíceas e clorofíceas. A clorofila “a” variou de $1,49 \mathrm{mg} / \mathrm{m}^{3}$ a $23,33 \mathrm{mg} / \mathrm{m}^{3}$. A Baía de Guajará é caracterizada por uma pequena variaçāo na salinidade, temperatura elevada, baixa transparência e pH geralmente ácido. A variação anual destes parâmeros está relacionada com o regime pluviométrico, que influencia os valores quantitativos dofitoplâncton.

TÍTULO: Microbiota fúngica e espécies produtoras de aflatoxina, ocratoxina e citrinina em castanha-do-Pará (Bertholletia excelsa Humbold e Bompland)

AUTORA: Solange do Perpétuo Socorro Evangelista Costa

DATA: $\quad$ Março de 1991

LOCAL: Universidade Federal de Pernambuco

NÍVEL: Mestrado

BANCA EXAMINADORA: Maria Auxiliadora de Q. Cavalcanti (orientadora) - UFPE Maria Menezes, - UFPE

Laíse de Holanda C. Andrade - UFPE

RESUMO: Uma grande variedade de produtos alimentícios consumidos pelo homem estāo sujeitos à contaminação por micotoxinas. A castanha-do-Pará constitui-se em um importante produto de exportação da regiāo amazônica além de ter amplo consumo entre esta população. Para avaliar a susceptibilidade destas amêndoas à contaminação por fungos e em especial pelos produtores de aflatoxina, ocratoxina e citrinina, foi realizado um estudo com amostras procedentes da cidade de Belém (PA-Brasil) e constituídas de castanhas beneficiadas, castanhas com casca e castanhas em ouriço. Estas sementes, após descorticadas, foram esterilizadas superficialmente e colocadas em câmara úmida. Isolou-se 1.199 taxa constituindo um total de 59 diferentes espécies. Destas, $78,57 \%$ pertencem à sub-divisão Deuteromycotina, seguida de Zygomycotina, Ascomycotina e Mycelia sterilia, com 15,93\%, 4,83\% e 0,67\%, respectivamente. Aspergillus, Syncephalastrum, Penicillium e Fusarium foram os gêneros mais assinalados. "Coconut Agar Medium" foi utilizado para detecçāo das referidas toxinas dos isolados, através da observação de fluorescência sob ondas longas de luz ultravioleta. As amostras positivas foram extraídas com clorofórmio e ensaiadas por cromatografia de camada delgada (CCD). Foram detectados 154 isolados produtos de aflatoxina, entre Aspergillus flavus e A. parasiticus, 2 de citrinina e 1 de ocratoxina, (Penicillium steckii $\mathrm{A}$. ochraceus respectivamente). A produçāode aflatoxina nas amêndoas também foi avaliada, através da incubaçāo de uma amostra toxigênica de $A$. parasiticus constatando-se a suscetibilidade do substrato. Outros aspectos referentes ao crescimento de fungos nas amêndoas também foram analisados. 